\title{
Android Application Usada Hindu Bali as an Effort to Maintain Traditional Indonesian Cultural Heritage
}

\author{
NE Rakhmawati ${ }^{1}$, I Agus ${ }^{2}$, Hendarman $^{3}$, A Nurhayati $^{4}$ and D Pratama ${ }^{5}$ \\ STIKes Istara Nusantara, Jakarta, Indonesia ${ }^{1}$ \\ Universitas Indraprasta PGRI, Jakarta, Indonesia ${ }^{2}$ \\ Universitas Bhayangkara Jakarta Raya, Indonesia ${ }^{3}$ \\ Akademi Teknik Telekomunikasi Sandhy Putra Jakarta, Indonesia ${ }^{4}$ \\ Universitas Indraprasta PGRI, Jakarta, Indonesia ${ }^{5}$ \\ \{nurendah_r@yahoo.com $\left.{ }^{1}\right\}$
}

\begin{abstract}
Rapid technological developments affect the way people do or get something. One of them is how to get information about health. The Usada Hindu Bali application is one example of obtaining information about traditional Balinese medicine by utilizing technological developments. This application was made using the Android version 4.4 Kit Kat platform created in 2013. Using a 10.6MB file size displays several menus including: Usada Meaning, Application Rate, Other Applications, and a list of diseases and names of traditional medicines. The Usada Bali Hindu application is not only valuable in technology but displays cultural and health values, so by providing information on traditional Balinese medicine it automatically elevates the value of Balinese culture. In terms of health this application offers traditional Balinese medicine, this provides an alternative choice, so that people can choose the treatment they like. The existence of the Usada Hindu Bali application is expected to improve the health status of the community by utilizing traditional medicine information through technology-based applications.
\end{abstract}

Keywords: Application, Usada Hindu Bali, Traditional Medicine, Health

\section{Introduction}

The development of health science is currently very rapid and influenced by various aspects of life, which is a paradigm shift, with many individuals turning to traditional medicine. This is caused by various factors, including economic factors. It is undeniable that the cost of expensive medical treatment in modern / medical medicine is the main reason for this migration, but medical treatment is still the first choice. If medical treatment requires a large fee and there is no change towards healing, then it is possible that people will begin to turn to traditional methods of treatment known as alternative medicine.

Supported by internet-based computer technology that is increasingly accessible makes it easier for the public to seek alternative medicine information, but not all information displayed on the internet has absolute truth value. Including in terms of traditional medicine when looking for related information, there will be many alternative traditional treatments that emerge. It takes an extra step of carefulness and thoroughness to sort the information found on 
the internet to find the intended information. To make it easier for someone to know the right information on traditional medicine, it can be presented in the form of an application. For example, the existence of Usada Hindu Bali, which is an android-based application that provides alternative medicine services, is now starting to attract many people.

\section{Literature review}

Android defines a new component-based framework where it was used generally to develop applications for mobile gadgets, where each application is comprised of different numbers and types of components [1]. Android is a modified mobile operating system based on the open source Linux operating system. Initially, it was developed by a startup from the Silicon Valley with the same name, Android, Inc. However, In 2005, Google launch a strategy to enter the mobile space competition and purchased Android, as well as its development team, and took over its development work [2].

Android is a Linux-based operating system (OS) that is very popular and widely known nowadays, this is because the Android OS is open source. It is undeniable that this operating system has taken a lot of attention from the world community including Indonesia. Gadget companies and cellular phones are competing to make devices using the Android operating system. Therefore, it is not surprising that almost every day we see new gadgets circulating in the market that use Google's operating system to create certain applications such as the Usada Bali Hindu Application which is released to discuss traditional medicine.

Based on the Law of the Republic of Indonesia No. 36 of 2009 concerning Health, Article 1 paragraph 8 states that drugs are materials or alloys of materials, including biological products that are used to influence or investigate physiological systems or pathological conditions in the framework of establishing diagnosis, prevention, healing, recovery, improving health and contraception, for humans. Whereas the statement on verse 9 states that traditional medicines are ingredients or materials in the form of plant materials, animal materials, mineral materials, herb, or a combination of these materials which is used for treatment for generations, and can be applied in accordance with the norm applicable in society [3].

According to the Regulation of the Minister of Health of the Republic of Indonesia No. 007 of 2012 concerning Registration of Traditional Medicines, traditional medicines are the extract (galenik) of herb or mixtures of the substances which have been hereditary used for treatment, and can be applied in accordance with applicable norms in the community[4].

\section{Result and discussion}

Traditional medicine is an alternative medicine that is very diverse in accordance with local culture and beliefs. In Hindu beliefs in Bali it is known as Usada medical science Bali and Balian as the doctor. The word Usada comes from Sanskrit, namely ausadha which means herbs which have medicinal properties, or are made from plants. Therefore, the Usada boundaries in Bali are broader Usada is all the procedures for curing diseases, ways of treatment, prevention, estimating the types of diseases / diagnoses, the course of the disease and its recovery. Along with the need for information on the existence of traditional medicine, the Usada Hindu Bali application was made so that it could be accessed by the public throughout the community. 
By using the Android application, we can search for information not just one type of disease, but several types of diseases in one application, so that the search is more efficient. In terms of content, based on the International Age Rating Coalition (IARC) this application has an application rate value of $3+$ which means that this application is suitable for all age groups. While from the reviewer, this application has 10 reviewers with 7 reviewers giving 5 stars (highest scores) and 3 others stating 3 stars.

The Usada Hindu Bali application is an application of Traditional Balinese Medicine, can run well on the Operating System version of Android 4.4 Kit Kat in 2013. At this time, the Android Operating System has reached 8.0 Oreos. However, the application is certain to work properly. The application runs off line, after the installation process to the tablet or smart phone. The following are the specifications of the Usada Bali Hindu Application:

a. The size of the application is not too large the size of the application installed is only $10.61 \mathrm{Mb}$.

b. The application can be used on tablet and smart phone devices, for the screen display according to the size of the tablet and smart phone screen, it does not affect the menu choices available overall menu selection will appear 18 menus, by sliding the screen up.

c. Display menu options are quite complete, there are 3 menus provide information, consisting of:

- Menu Meaning Usada to find out the meaning of Usada namely traditional Balinese medicine

- APP Rate menu which functions to provide Application Rate or Values on the Google Play Store, another application menu functions to install other applications that have something to do with Bali on Google Play Store consisting of Daily Prayer Applications, Song of God Yadnya and Typical Recipes of Bali

- In addition to the information menu from Meaning Usada, the Rate menu and the Menu to install other Applications, there are also 15 menus providing information for the treatment of diseases, there are several types of diseases, displaying diseases related to the parent from the selected disease menu, for example a skin disease menu. featuring menus, Dragon Rinse, Flower Rinse, Leprosy, Leprosy and Skin Allergies. The type of disease shown does not include serious illness, like Diabetes, eventhough this is very important. World Health Organisation (WHO) predicts that by 2030, diabetes will be the seventh leading cause of death in the world [5].

d. The application's colour display is quite comfortable, black writing, white background, there is a soft background wallpaper in the menu options. The disadvantage of the information presented is that the medicinal materials used are plant species which are generally familiar or understood by the Balinese people, and there is no display of photos of medicinal materials consisting of various types of plants.

e. Another disadvantage to leaving the application is that there is no "menu question whether to exit or not from the application", so to exit, after touching the screen with the back arrow button on the tablet or smart phone, the application will immediately exit.

f. This application is quite good because it tries to display other applications related to Bali, only when it is clicked has it not been connected with the application in question, so the Application Usada Hindu Bali should show other applications whose applications are running hand in hand. 
g. It is better if the application is added contact us or there is a question and answer column online or you can also display some of the names of traditional drug stores that are back, so when we click the drug store it is directly connected to the Google map to the traditional drug store.

\section{FLOW SYSTEM}
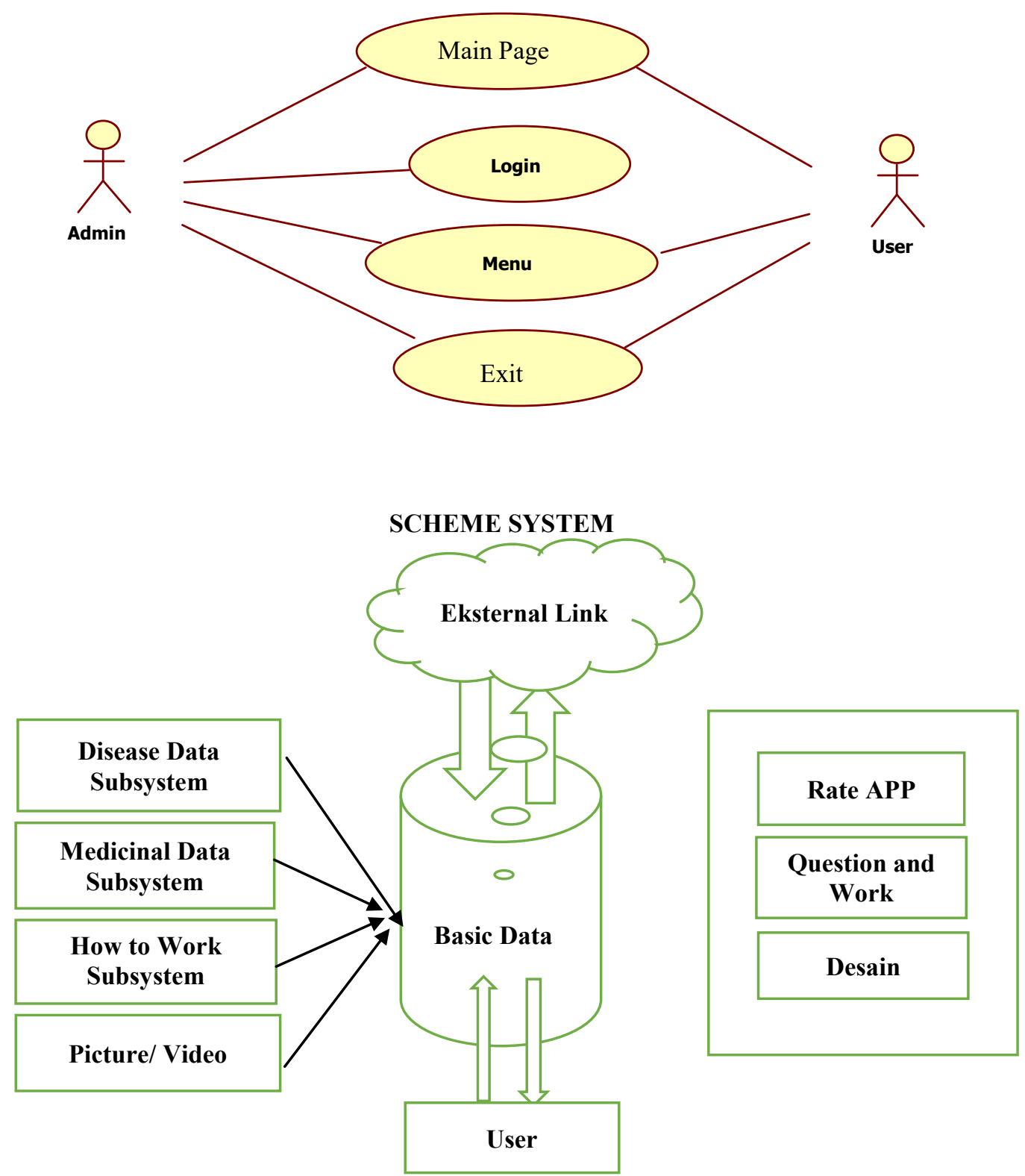
Model Use case grooves used in this application:

a. Admin enters the main menu.

b. Admin data entry Meaning Usada

c. Admin entry data rate application.

d. Admin data entry other applications.

e. Admin for data on Disease and Medicine.

f. Admin updates on data on the application

g. Admin does exit and exit the application.

$\mathrm{h}$. The user enters the main menu.

i. User issues information issues from the designated menu. Users do exit and exit the application

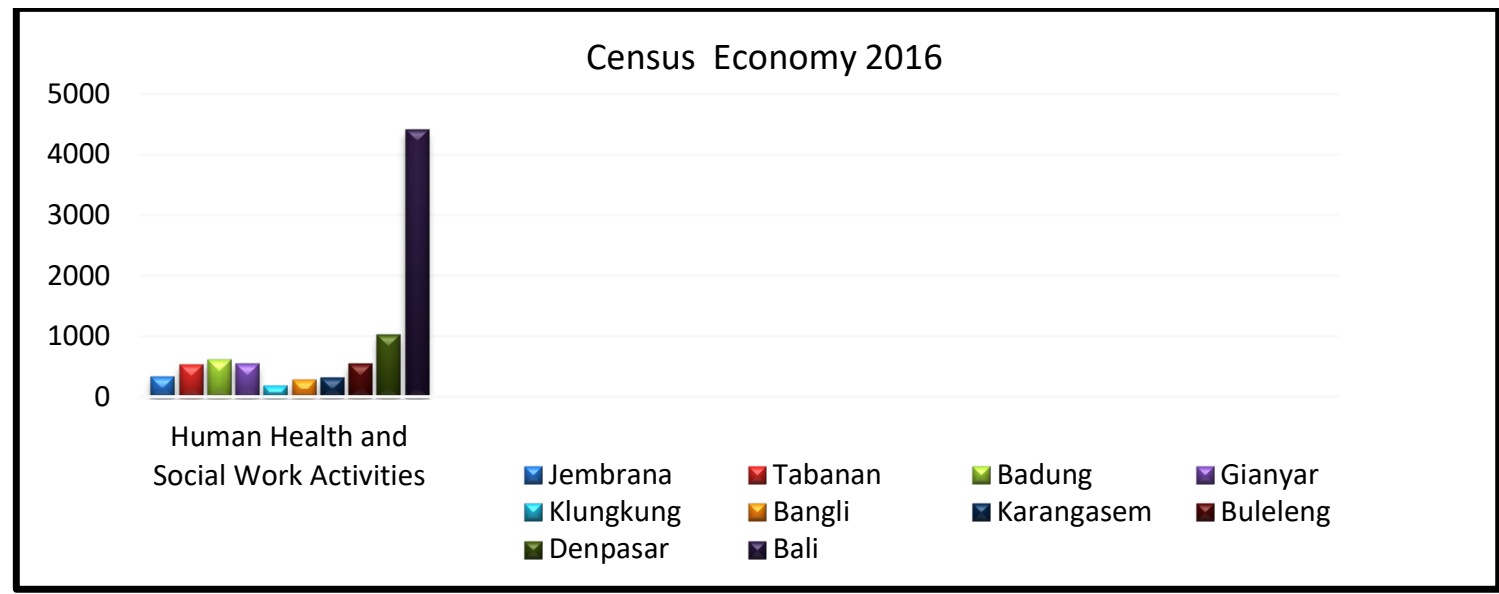

Figure 1. Human Health Activities and Social Activities[6]

Based on data from the 2016 Economic Census[6], the development of business/ activity in the health sector and social activities in general in Bali Province is quite fast this illustrates the interests and hopes of the community using health and social services that are large enough to improve welfare and opportunities to create employment more.

For example, Rheumatoid Arthritis (RA) is a chronic autoimmune disease where inflammation progresses in the synovial and cartilage joints and bone damage. Most of the drugs used for the treatment of RA have severe and very expensive side effects. Therefore, the proportion of patients using Complementary and Alternative Medicine (CAM) has increased recently. The prevalence of CAM use varies from $28 \%$ to $90 \%$, in RA patients it is reported that the most commonly used CAMs are biological products, such as honey, and herbal medicines such as rosemary, ginger, borage and others. This CAM choice is due to the fact that herbal medicines are easily available, have low levels or no side effects, are cheap, and may be safe and efficient. Some researchers have indicated that herbal medicines and food products have succeeded in giving a preventive effect to some diseases. Other studies also show that consumption of coffee and green tea, alongside with the use of herbal medicines, medicinal plants, and functional foods as natural products might prevent and can be used to 
treat chronic inflammatory diseases, such as RA patients who use medicinal plants to cure diseases or relieve symptoms [7]. Some medicinal plants are also being reported to have a relieving effect to the case of menstrual symptoms through their analgesic, anti-spasmodic, prostaglandin inhibiting, or anti-inflammatory actions. The use of these medicinal plants could become a suitable alternative to treat dysmenorrhoea, particularly in cases where the patients did not tolerate the conventional medicines well and the use of such medicines are contraindicated. However, the way these medicinal plants work in relieving these symptoms is not well understood and needs to be studied further [8].

In the other research for serious disease like Diabetes, A total of 400 diabetic patients were interviewed, 206 were female $(51.5 \%)$. The mean age of participants was $54.0 \pm 10.1$ years. CAM use in female patients was significantly more frequent. The frequency of CAM use was statistically higher in patients with age of 50-64 years. Although statistically, there were no significant differences between the CAM users and the non-users in terms of income status, educational level, body mass index, duration of diabetes, and knowledge of diabetes, the area of residence was statistically more frequent in city for those of CAM users. $93.1 \%$ of CAM users believed that the herbal medicine would play an important role on decreasing the progression of the Diabetic[9].

The existence of the Usada Hindu Bali Application is good, only when viewed from the point of view of disease material, there is still no explanation of each disease so that the reader will perceive the meaning of the disease itself and there is the possibility of guessing according to the illness. Besides that it would be more perfect if accompanied by complaints (signs and symptoms) related to each disease. In the Usada Hindu Bali Application if viewed from the diversity of types of diseases shown not yet representing all diseases in each part of the disease, it is better to share the disease based on Organ and Organ System so that all types of diseases are covered [2].

\section{References}

[1] S. Holla and M. M. Katti, "Android Based Mobile Application Develeopment and its Security,” Int. J. Comput. Trends Technol., vol. 3, no. 3, pp. 486-490, 2012.

[2] W.-M. Lee, Beginning Android Application Develeopment in Full Color. New Jersey: Wiley Publishing, Inc., 2011.

[3] "Law of Republic of Indonesia Number 36 Year 2009 concerning Health.” 2009.

[4] "Regulation of the Minister of Health of the Republic of Indonesia Number 007 Year 2012," vol. Unknown, no. Unknown. p. No Pages, 2012.

[5] D. N. Pender, P. F. Crawford, J. M. Clark, A. J. Crawford, A. A. Prats, and S. A. Shah, "Effect of water-soluble cinnamon extract on electrocardiographic parameters: An analysis of the CiNNaMON trial," Complement. Ther. Med., vol. 41, no. September, pp. 302-305, Dec. 2018.

[6] Central Bureau of Statistics Bali Province, “Census Economy 2016,” 2017.

[7] S. C. Smeltzer, B. G. Bare, J. L. Hinkle, and K. H. Cheever, Brunner \& Suddarth's Textbook of Medical-Surgical Nursing, 12th ed. Philadelphia: Wolters Kluwer Health / Lippincott Williams \& Wilkins, 2010.

[8] J. Pellow and C. Nienhuis, "Complementary Therapies in Medicine Medicinal plants for primary dysmenorrhoea : A systematic review," Complement. Ther. Med., vol. 37, no. December 2017, pp. 13-26, 2018.

[9] D. İ. Yıldırım and K. Marakoğlu, "Complementary and alternative medicine use 
amongst Turkish type 2 diabetic patients: A cross-sectional study," Complement. Ther. Med., vol. 41, no. March, pp. 41-46, Dec. 2018. 